\title{
NOCARDIAL INFECTIONS: REPORT OF 22 CASES
}

\author{
Maria Bernadete F. CHEDID(1), Marcio F. CHEDID(2), Nelson S. PORTO(3), Cecília B. SEVERO(4) \& Luiz Carlos SEVERO(4,5)
}

\section{SUMMARY}

Twenty-two cases of nocardial infections were diagnosed in our city between 1977- 1998. All patients whose clinical specimens showed Nocardia spp. at Gram stain, which were further confirmed by culture, were selected to be included in the study. Data from patients who were cured were compared with those from patients who died by statistical tests using EPIINFO version 6.04 software. Six isolates were identified as Nocardia asteroides complex, one as Nocardia asteroides sensu stricto and other as Nocardia brasiliensis. We had 17 cases of lung nocardiosis, being one out of them also a systemic disease. Other four cases of systemic nocardiosis were diagnosed: nocardial brain abscesses (one); nocardiosis of the jejunum (one); multiple cutaneous abscesses (one); and a case of infective nocardial endocarditis of prosthetic aortic valve. One patient had a mycetoma by $N$. brasiliensis. Fifteen (68.2\%) out of 22 patients were immunosuppressed, being most (93.3\%) by high-doses corticotherapy. Mortality by nocardial infection was $41 \%$; mortality of systemic nocardiosis was $60 \%$. Nocardiosis has a bad prognosis in immunosuppressed patients and also in non-immunosuppressed patients if the diagnosis is delayed. We propose that the delay in diagnosis should be examined in larger series to document its influence in the prognosis of the disease.

KEYWORDS: Nocardia species; Nocardial infection; Pulmonary nocardiosis; Systemic nocardiosis; CNS nocardiosis; Cutaneous nocardiosis; Small bowel nocardiosis; Nocardial endocarditis.

\section{INTRODUCTION}

Nocardiosis is a worldwide disease known as an infection that affects predominantly patients with immunodepressive diseases ${ }^{3}$. The microorganism was first described by Nocard in 1888 as a fungus and was further classified as an aerobic bacteria that belongs to the genus Nocardia, order Actinomycetales. They are saprophytic organisms ubiquitous in nature, commonly isolated from soil, typically filamentous, aerobic branching gram-positive bacteria whose bacterial filaments fragment to coccobacillary forms.

Species more associated with infections in humans are $N$. asteroides (sensu stricto), N. brasiliensis, $N$. farcinica and $N$. nova; less commonly $N$. otitidiscaviarum and N. pseudobrasiliensis; and rarely associated, or whose prevalence is not yet established: $N$. abscessus, $N$. brevicatena complex, $N$. africana, $N$. paucivorans, $N$. asteroides type IV, $N$. carnea, $N$. transvalensis and N. veterana ${ }^{28}$.

In this study, we present clinical and microbiological characteristics; treatment and outcome of 22 cases of nocardial infection diagnosed in our laboratory for a period of twenty-two years.

\section{MATERIALS AND METHODS}

We retrospectively revised through database analysis all cases of nocardial infections diagnosed between January 1977 and December 1998 in our mycology laboratory that serves two reference hospitals (respectively of 735 and 1,100 beds) in an urban center with 1.4 million inhabitants in Southern Brazil.

Clinical data were collected at the time of laboratorial diagnosis and most patients had follow-up for at least one year. Eventually we reviewed the laboratory data and the hospital files again in order to collect all necessary data.

Clinical specimens for laboratory examination were pus, sputum, bronchial secretions, pleural effusions drawn by thoracentesis; percutaneous needle aspirates of the lung, or surgically removed tissue. Pus and grains were mounted in a drop of $10 \%$ potassium hydroxide; pus and smashed grains, sputum or sediment of bronchoalveolar lavage or lung aspirates were smeared and stained by Gram's technique. Cut sections of tissues were stained by $\mathrm{H} \& \mathrm{E}$ and Brown-Brenn techniques. If either branching, Gram-positive thin filaments compatible with Nocardia spp. were seen at Gram stain, it was performed the modified Kinyoun stain and the Ziehl-Nielsen stain to the acid-fastness examination. Further the clinical specimen was cultured in Sabouraud's dextrose agar and incubated aerobically at room temperature and at $37^{\circ} \mathrm{C}$ for one week. If colonies suggestive of Nocardia spp. grew in at least one culture media, extended cultures were performed in Lowenstein-Jensen media. Genus identification of Nocardia spp. was

Financial Support: Coordenação de Aperfeiçoamento de Pessoal de Nível Superior (CAPES, Brazil); National Counsil of Technological and Scientific Development (CNPq, Brazil); Grupo de Pesquisa e Pós-Graduação (GPPG) of Hospital de Clínicas de Porto Alegre, Brazil.

(1) Hospital de Clínicas de Porto Alegre and Santa Casa de Misericórdia Hospital, Federal University of Rio Grande do Sul, Porto Alegre, RS, Brazil.

(2) Department of Surgery, Hospital de Clínicas de Porto Alegre, Federal University of Rio Grande do Sul, Porto Alegre, RS, Brazil.

(3) Radiology Service, Pavilhão Pereira $F^{\circ}$ Hospital, Santa Casa de Misericórdia de Porto Alegre, RS, Brazil.

(4) Laboratory of Micology, Santa Casa de Misericórdia de Porto Alegre, Porto Alegre, RS, Brazil.

(5) Post- Graduate Program in Pulmonology, Federal University of Rio Grande do Sul.

Correspondence to: Maria Bernadete F. Chedid, Rua Ramiro Barcelos 910/903, 90035001 Porto Alegre, RS, Brasil. Tel: +55 51 33282472, Fax: +55 51 3311 7461. E-mail: mariab@ terra.com.br 
based upon appearance at either Gram stain or modified Kinyoun stain; and colony morphology: isolates had macroscopic aerial bacterial filaments and microscopic long, thin, branched filaments. Each microorganism was subcultured on plates containing casein, gelatin, tyrosine, xanthine and urea ${ }^{28}$. Some isolates were sent to CDC at the time of diagnosis to confirm or to define the species of Nocardia, but attempts were not made at our laboratory to distinguish members of N. asteroides complex until 1994.

We classified our cases as others ${ }^{3}$ as:

1) Pulmonary nocardiosis when the lung was involved;

2) Extrapulmonary nocardiosis when other organs were involved without the concomitant involvement of the lung, but we distinguish CNS nocardiosis when the brain was involved, requiring to it the isolation of Nocardia sp. from brain lesion;

3) Mycetoma was classified as a primary skin infection being a local, chronic, slowly progressive destructive infection of the skin, subcutaneous tissues, fascia, bone and muscle, containing suppurative granulomas and multiple sinus tracts that extrude grains;

4) Systemic nocardiosis: when the infection has disseminated to the blood or to at least one more non-contiguous organ. Either the finding of a brain lesion proved of nocardial origin; the isolation of Nocardia spp. from a patient with arthritis; the finding of multiple nocardial cutaneous lesions; or the isolation of Nocardia spp. from gastrointestinal lesions were all classified as systemic nocardiosis since it is presumed that the infection has originated from a primary foci, from where it has disseminated giving infectious "metastatic" lesions to such organs. The isolation of Nocardia species from subphrenic and subhepatic abscess in a patient with adjacent pleural nocardiosis was considered localized nocardiosis, since the dissemination of the disease should have occurred through local lymphatic channels.

Underlying chronic disease was defined as presence of heart disease, liver disease, renal disease, lung disease or diabetes mellitus. Immunosuppression was defined as presence of HIV infection, previous splenectomy, hematological malignancy, autoimmune disorder, transplant recipients and receipt of cancer chemotherapy within four weeks ${ }^{35}$ or prednisolone use of at least $10 \mathrm{mg} /$ day (or equivalent doses of other steroids) in the last three months.

Time in diagnosis was defined as the mean duration of the disease from the onset of the symptoms to the time of the diagnosis and prescription of appropriated antibiotics against Nocardia spp. The diagnosis was defined as "ante mortem" when the patient survived seven days or less after the prescription of appropriated antibiotics for nocardial infection.

Data were entered and analyzed using EPIINFO version 6.04D software. Data from patients with nocardiosis who were cured were compared with those from patients who died. Differences between frequencies of categorical variables were determined using the chisquared test or Fisher exact test. Time to diagnosis between the group of patients who died and the group which survived was compared using the Mann-Whitney test. Statistical comparisons were performed at a $5 \%$ level of significance for a 2-tailed test.

\section{RESULTS}

Between 1977 and 1998 were diagnosed 22 cases of nocardial infections (see Tables 1 and 2), being 10 females and 14 males with a mean age of 45.5 years (range, 21-72). They are numbered consecutively since the first two Brazilian patients (1 and 2) were diagnosed ${ }^{25}$.

Etiological diagnosis: Six isolates were identified in our laboratory as Nocardia asteroides complex (patients 1, 2, 4, 5, 7, 12), one isolate as Nocardia asteroides sensu stricto type I (patient 22) and one isolate as Nocardia brasiliensis (patient 6) on basis of their non-degradation of casein, tyrosine, xanthine, hypoxanthine and adenine, and production of urease ${ }^{28}$. Some cases were confirmed by the CDC of Atlanta at the time of diagnosis: case 1 (094407/77 CDC), case 4 (3882083550/82 CDC), case 6 (3888015409/88 CDC) and case 7 (041849/84 CDC). We did not provide species identification for 14 isolates and they are here described as Nocardia spp.

Clinical and radiological presentation: Seventeen cases of lung nocardiosis were diagnosed and the disease was restricted to lung in sixteen of these cases, while in one case (patient 8) it was disseminated (Table 1). We had five cases of systemic nocardiosis (Table 2): one case of nocardial skin abscesses with concomitant arthritis; one case of CNS nocardiosis; one case of small bowel nocardiosis; one case of endocarditis of prosthetic aortic valve and one case of lung nocardiosis with Nocardia spp. isolated both from the lung and from an axillary abscess (patient 8 , Table 1). And finally we had one case of mycetoma by Nocardia brasiliensis. Data of all patients are summarized in Tables 1 and 2, except the patient with mycetoma, who is described separately.

Lung nocardiosis: Our seventeen cases of lung nocardiosis are summarized in Table 1, where we can see that five (29.4\%) patients had no immunosuppression, being one patient (number 8) previously healthy. The other $12(70.6 \%)$ patients had immunosuppression.

All but one of the seventeen patients with lung nocardiosis initially complained of productive cough. The most common radiological presentation of lung nocardiosis was consolidation (Fig. 1) which occurred in 10 patients (58.8\%). Lung cavities (Fig. 2 and 3) were found in nine patients $(52.9 \%)$. Pleural fluid and pulmonary nodules (Fig. 4) were found respectively in five patients (29.4\%). The diagnosis was done in seven $(41.2 \%)$ patients by percutaneous needle aspiration and in four patients only in the sputum; while in other two patients it could be only done by open lung biopsy.

Ten patients were treated with TMP-SMX while five took sulfadiazine and two patients used both drugs, sequentially, due to a relapse. In only five cases either sulfadiazine of TMP-SMX were used in combination with beta-lactams (oxacillin, ampicillin), minocycline, cycloserin or amikacin. Seven out of 17 patients (41.2\%) with lung nocardiosis were cured, while 10 died (58.8\%). Among these 10 patients who died, three deaths (patient 2, 10 and 12) were not directly attributed to nocardiosis: in the former two patients, the cause of death was attributed to brain tumor of unknown etiology; while in patient 12 , 
Table 1

Nocardial lung infections in 17 patients in Porto Alegre (Brazil) 1977-1998

\begin{tabular}{|c|c|c|c|c|c|c|}
\hline $\begin{array}{l}\text { Case } \\
\text { number }\end{array}$ & Age/Sex & $\begin{array}{l}\text { Primary } \\
\text { site }\end{array}$ & $\begin{array}{l}\text { Secondary } \\
\text { site }\end{array}$ & Etiology & $\begin{array}{l}\text { Underlying diseases or associated } \\
\text { conditions of immunosuppression }\end{array}$ & Evolution \\
\hline 1 & 39 / M & Lung & - & N. asteroides & COPD & Cure \\
\hline 2 & $46 / \mathrm{F}$ & Lung & - & N. asteroides & Brain cancer, COPD, Corticotherapy & Death \# \\
\hline 3 & $49 / \mathrm{F}$ & Lung & & $N$. spp. & SLE, Chemotherapy, Corticotherapy & Death \\
\hline 4 & $30 / \mathrm{M}$ & Lung & $\begin{array}{l}\text { Pleura, } \\
\text { abdomen }\end{array}$ & N. asteroides & Kidney transplant, Chemotherapy, Corticotherapy & Cure \\
\hline 5 & $21 / \mathrm{F}$ & Lung & Pleura & N. asteroides & Kidney transplant, Chemotherapy, Corticotherapy, & Cure \\
\hline 7 & $56 / \mathrm{M}$ & Lung & - & N. asteroides & Hepatitis, COPD, diabetes, Corticotherapy & Death \\
\hline $8 *$ & $57 / \mathrm{F}$ & Lung & Axillary node & N. spp. & No & Death \\
\hline 9 & $28 / \mathrm{F}$ & Lung & - & N. spp. & $\begin{array}{l}\text { Hodgkin's Lymphoma, Chemotherapy, Radiotherapy, } \\
\text { Corticotherapy }\end{array}$ & Death \\
\hline 10 & $34 / \mathrm{F}$ & Lung & Brain? NB & N. spp. & Breast cancer, Radiotherapy, Corticotherapy, & Death \# \\
\hline 11 & $46 / \mathrm{F}$ & Lung & - & $N$. spp. & $\begin{array}{l}\text { Breast cancer, diabetes, Polymyositis, Chemotherapy, } \\
\text { Radiotherapy, Corticotherapy }\end{array}$ & Cure \\
\hline 12 & $71 / \mathrm{M}$ & Lung & - & N. asteroides & AIDS, COPD & Death \# \\
\hline 13 & $45 / \mathrm{M}$ & $\begin{array}{l}\text { Lung } \\
\text { (Pleura) }\end{array}$ & - & $N$. spp. & Lung cancer, Radiotherapy & Cure \\
\hline 15 & $25 / \mathrm{M}$ & Lung & - & $N$. spp. & Polymyositis, Corticotherapy & Cure \\
\hline 16 & 46 / M & Lung & Brain? NB & N. spp. & COPD & Death \\
\hline 19 & $57 / \mathrm{M}$ & Lung & - & $N$. spp. & Liver transplant, Chemotherapy, Corticotherapy & Death \\
\hline 21 & $55 / \mathrm{F}$ & Lung & - & N. spp. & Chronic bronchitis, lung fibrosis lesions after TB & Death \\
\hline 22 & $50 / \mathrm{F}$ & Lung & - & $\begin{array}{l}\text { N. asteroides } \\
\text { Sensu stricto } \\
\text { type I }\end{array}$ & Asthma, Corticotherapy & Cure \\
\hline
\end{tabular}

a) Patient number 6 is not included in any table because he had a skin infection only; he had a mycetoma by $N$. brasiliensis. b) Patient number 8 is the fifth case of systemic nocardiosis. c) *Proven case of systemic nocardiosis by isolation of Nocardia spp. in other organs or other skin regions, or in the blood. d) NI - Not identified. e) NB: No Biopsy done. f) - No secondary foci of infection. g) \# Death not attributed to nocardiosis.

Table 2

Systemic nocardiosis in Porto Alegre (Brazil) 1977-1998 §

\begin{tabular}{|c|c|c|c|c|c|c|c|}
\hline $\begin{array}{l}\text { Case } \\
\text { number }\end{array}$ & Age/Sex & $\begin{array}{l}\text { Primary } \\
\text { site }\end{array}$ & $\begin{array}{l}\text { Secondary } \\
\text { site }\end{array}$ & Etiology & $\begin{array}{l}\text { Underlying diseases or associated } \\
\text { conditions of immunosuppression }\end{array}$ & Treatment & Evolution \\
\hline $14 *$ & $42 / \mathrm{M}$ & NI & $\begin{array}{l}\text { Skin abscesses, } \\
\text { septic arthritis }\end{array}$ & $N$. spp. & $\begin{array}{l}\text { Multiple sclerosis, DPOC, } \\
\text { Diabetes, Corticotherapy }\end{array}$ & TMP-SMX one year & Cure \\
\hline $17 *$ & $60 / \mathrm{M}$ & NI & Brain & $N$. spp. & $\begin{array}{l}\text { Larynx cancer. Non-Hodgkin } \\
\text { lymphoma } \\
\text { Chemotherapy, Radiotherapy, } \\
\text { Corticotherapy }\end{array}$ & TMP-SMX/13 days & Death \\
\hline $18 *$ & $44 / F$ & NI & Jejunum & N. spp. & $\begin{array}{l}\text { Liver transplant, Chemotherapy, } \\
\text { Corticotherapy }\end{array}$ & $\begin{array}{l}\text { Imipenem plus } \\
\text { Vancomycin/10 days }\end{array}$ & Death \\
\hline $20 *$ & $40 / \mathrm{M}$ & NI & $\begin{array}{l}\text { Blood } \\
\text { aortic prosthesis }\end{array}$ & N. spp. & No & $\begin{array}{l}\text { Sulfadiazine plus } \\
\text { amikacin six weeks } \\
\text { followed by } \\
\text { TMP-SMX/6 months }\end{array}$ & Cure \\
\hline
\end{tabular}

a) * Systemic nocardiosis by isolation of Nocardia spp. in other organs or other skin regions, or in the blood. b) $\S$ Patient 8 is the fifth case of systemic nocardiosis and he is included as lung nocardiosis in Table I. c) NI - Not identified. 


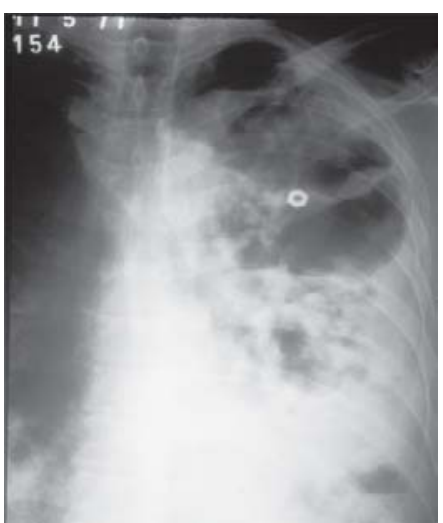

Fig. 1 - Chest X-Ray of patient 1 showing consolidations in left lung with many cavitations and a foci of consolidation in IRL.The metallic circle is to guide the percutaneous needle aspiration maneuver.

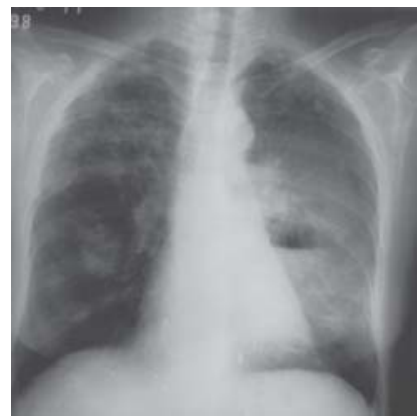

Fig. 2 -Chest X-Ray of patient 2 showing multiple pulmonary nodules in both lungs, being one at right excavated with thick walls; also we can see consolidations in the SRL; the biggest nodule is excavated (at left lung), with retained secretions and liquid level.

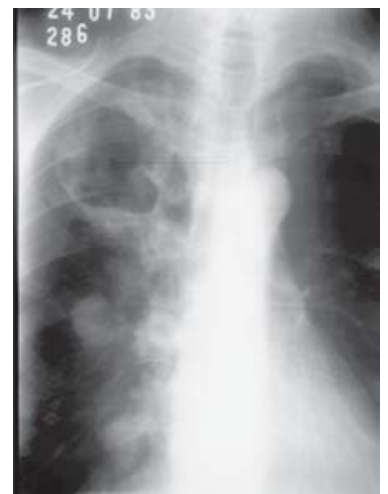

Fig. 3 - Chest X-Ray of patient 7 showing a nodule and a huge cavity with thick walls in SRL.

who had advanced AIDS with multiple infections, the pulmonary nocardiosis was considered just a contributing cause of death.

CNS nocardiosis: Patient number 17 was a 60 year-old alcoholic man who underwent radiotherapy to a larynx cancer seven years ago; he was on chemotherapy due to a non-Hodgkin lymphoma of small bowel when he was admitted with fever, headache and drowsiness. No lung abnormality was noticed either at Chest X-Ray or at

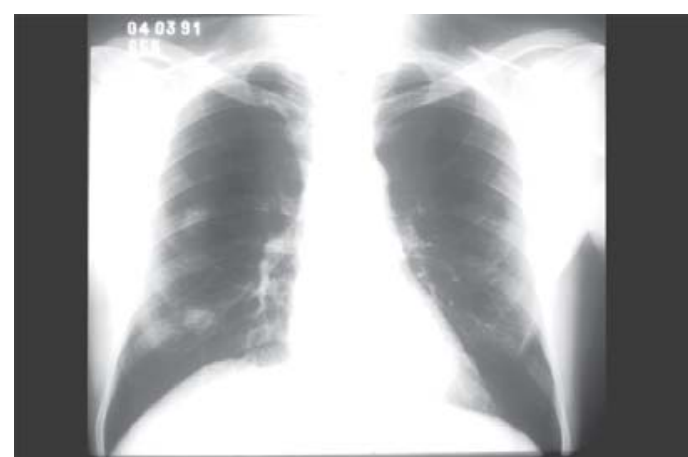

Fig. 4 - Chest X-Ray of patient 16 showing pulmonary nodules.

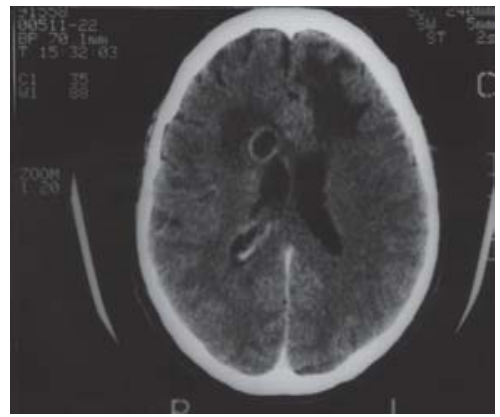

Fig. 5 - Brain CT of patient 17 showing an area of low density in the frontal lobe at right, ring-shaped, compressing both the head of caudate nucleus and the anterior horn of lateral ventricle.

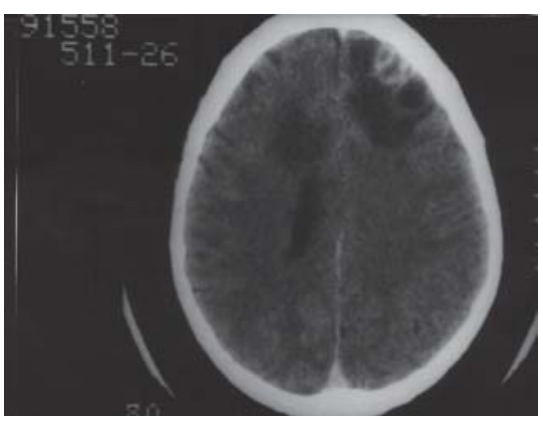

Fig. 6 - Brain CT of patient 17 showing another ring-shaped area of heterogeneous density in the left frontal lobe.

fiberbronchoscopy. Brain CT showed two masses in both frontal lobes (Fig. 5 and Fig. 6) and a craniotomy was performed for drainage of these two abscesses, in which pus Nocardia spp. was diagnosed. He received dexamethasone $16 \mathrm{mg} /$ day and IV TMP/SMX $2 \mathrm{~g}$ q6h plus amikacin and ceftazidime but died after 23 days. Patients 10 and 16 (Fig. 4) had both pulmonary nocardiosis and associated brain nodules. As we could not obtain brain tissue for microbiological analysis we could not classify both cases as CNS nocardiosis.

Systemic nocardiosis: We had five cases of systemic nocardiosis: Nocardia spp. was isolated in patients 14, 17 and 18 respectively from skin, brain and jejunum which were the secondary organs of nocardial infection; Nocardia spp. was also isolated from an axillary lymph node 
of a patient with lung nocardiosis (patient 8); and finally it was isolated from the blood in patient 20 (see Table 2) who had infective endocarditis of the aortic valve prosthesis. In all systemic nocardiosis patients we could not identify the primary organ affected except in patient 8 (see Table 1); in this latter patient, the lung was the primary organ affected by Nocardia spp. from where the infection disseminated, being Nocardia spp. isolated from an axillary lymph node.

Patient number 14 was admitted with multiple cutaneous abscesses (in the groin, in upper back, in the buttock, in the neck) and nodule in the left forearm; swelling and pain in the right knee and both left and right elbow - reason why he was classified as having systemic nocardiosis.

Patient 18 was on prednisone $20 \mathrm{mg} /$ day and cyclosporine $450 \mathrm{mg} /$ day for eight months after orthotopic liver transplantation, when she was admitted with abdominal pain and fever. She underwent enterectomy due to a lesion of transverse colon which was not cancer and it was diagnosed as "colitis". As she had leukopenia and peritonitis some days later, she underwent a laparotomy and a fistula between ileum and colon was seen. A proximal resection of jejunum and ileum was performed and Gram and culture of surgically removed tissue revealed Nocardia spp. She was treated with IV imipenem $500 \mathrm{mg}$ q6h plus vancomycin $500 \mathrm{mg}$ q6h but had to undergo to a new laparotomy after five days due to another abdominal abscess and died after six days.

Patient 20 was a 40 year-old farmer on anticoagulants due to prosthesis of aortic valve and a tricuspid valvuloplasty eight years before. He was admitted with axillary temperature of $38.2^{\circ} \mathrm{C}$, chills and myalgias. Transthoracic echocardiogram showed aortic regurgitation and vegetations on the prosthetic valve with paravalvar leak with minimal aortic insufficiency. Blood samples for culture were drawn. Due to the hypothesis of infective endocarditis he was prescribed IV gentamycin plus IV penicillin $G$ but he remained with fever. As two blood samples drawn with an interval of 14 hours grew Nocardia spp. sulfadiazine was added and the patient improved. Fifteen days later he presented fever again and a suppurative phlebitis of the right arm with bacteremia was diagnosed. Then a new blood culture drawn grew E. coli resistant to gentamycin, which was replaced by amikacin; the IV catheter was removed and the patient had clinical improvement. After six weeks the patient was discharged on PO TMP-SMX 160/800 $\mathrm{mg}$ q12h for six months. Transthoracic echocardiogram after 12 months showed no more vegetation in aortic prosthesis, and the patient remained well until 2004, when new transthoracic ecochardiogram showed only minimal mitral valve regurgitation, along with hypo contractile left ventricle.

Mycetoma: Patient 6 had a mycetoma caused by N. brasiliensis and was discharged from hospital on sulfadiazine. He came back four years later with a relapse of mycetoma lesions, telling that stopped taking sulfadiazine after 3-4 months of treatment, as soon the foot lesions healed. He then received TMP-SMX for at least six months but did not come back.

Immunosuppression, treatment and mortality: Seven patients $(31.8 \%)$ of our series (cases 1, 6, 8, 13, 16, 20 and 21) had no immunosuppression that could contribute to the infection by Nocardia spp. (See Tables 1 and 2). Three out of them died (42.8\%).
Immunosuppressive diseases were found in fifteen patients $(68.2 \%)$ : one patient (6.6\%) suffered from AIDS; two patients had hematological cancer (13.3\%); two (13.3\%) had autoimmune disorder; four patients $(26.6 \%)$ were transplant recipients; in the remaining six patients $(40 \%)$ immunosuppression was caused by high-doses corticotherapy due to solid cancer (three patients), asthma (one patient) or multiple sclerosis (one patient).

Corticotherapy was the main immunosuppressive condition being used in 14 out of 15 immunosuppressed patients (93.3\%); $10(71.4 \%)$ out of 14 patients on steroids were using either cytostatic drugs, radiotherapy or both. Seven patients $(50 \%)$ were taking corticosteroids in a doses greater than prednisolone $10 \mathrm{mg} /$ day (median prednisolone doses $=30 \mathrm{mg} /$ day) for a period between four months and five years. In the other seven patients (who were taking steroids for less than three months) the median daily prednisolone dose was greater than 50 $\mathrm{mg} /$ day. Nine out of fifteen immunosuppressed patients died, but in only six cases $(40 \%)$ the death was attributed directly to nocardiosis.

Three patients $(13.6 \%)$ had diabetes, being in all cases associated with the use of high-dose steroids. Chronic obstructive pulmonary disease (COPD) occurred in six patients $(27.3 \%)$ but mostly (in four patients) it was associated either with severe immunodepressive diseases or to the use of high-doses corticosteroids or both (see Tables 1 and 2).

Sulfa derivatives (TMP/SMX or sulfadiazine) either alone or in combination with other antibiotics were used for the treatment of these patients except one, who used imipenem plus vancomycin (patient 18). TMP-SMX was used in 13 (59\%) patients and sulfadiazine was used in four $(18.1 \%)$ patients. Both drugs were used sequentially in four (18.1\%) patients whose nocardial infection relapsed respectively due to short course of treatment (patient 6), due to intolerance (patient 10) or another reasons (patients 11 and 20).

From 22 patients of our series, nine deaths were attributed to nocardial infection, so mortality by nocardial infection was $41 \%$; while 10 cases obtained cure (45.4\%). Time to diagnosis (data not shown) between the group who died (mean 29.4 days, standard deviation 29.67) and the group who survived (mean 36 days, SD 32.64) compared by Mann-Whitney test showed no statistical significant difference between groups. In six out of nine patients whose death was directly attributed to nocardiosis the diagnosis of nocardial infection and the prescription of appropriated antibiotic was ante mortem, i.e., they received sulfadiazine or TMP-SMX for less than seven days before death (mean $=6.5$ days).

Although the delay in diagnosis in the group of patients with systemic nocardiosis who died (three patients, 41.3 days, SD 30.61), and the delay in the group of patients who survived (two patients, eight days, SD 4.24) suggests the delay in the diagnosis might have contributed to death in patients with disseminated nocardiosis, it did not reach a level of statistical significance. Statistical analysis between patients who died also showed that the patients who took sulfadiazine did not die more than the group who took TMP-SMX at a 5\% level of significance for a 2-tailed test.

Mortality of nocardial infection in our series was $41 \%$, being $40 \%$ 
in the group of immunosuppressed patients $(n=15)$ and $43 \%$ (three out of seven) in the group of non- immunosuppressed patients - thus we found no statistical significant difference at a $5 \%$ by Person ChiSquared test or Fisher exact test regarding immunosuppression between patients who died compared to the ones who survived.

Seven out of 17 patients with pulmonary nocardiosis died $(41.2 \%)$ Systemic nocardiosis had a mortality of $60 \%$ (three out of five cases).

\section{DISCUSSION}

Nocardial infections in USA are most frequently caused by $N$. asteroides sensu stricto type VI, N. brasiliensis, N. farcinica, and N. otitidiscaviarum $^{28}$. In Germany the predominant species identified is $N$. farcinica $(60.3 \%)^{29}$. In Japan 303 cases of nocardiosis were diagnosed showing that most were caused by $N$. asteroides complex $(72.3 \%)$, being $N$. farcinica the predominant species (81 strains) followed by $N$. asteroides (72 strains) and $N$. brasiliensis (66 strains) $)^{17}$; while in France $66.7 \%$ of isolates were $N$. asteroides and $23.8 \%$ were $N$. farcinica ${ }^{6}$ In Brazil the reported lung infections were caused by $N$. asteroides complex ${ }^{25,27}$. This is the largest series of nocardial infections in Brazil since we published the first two pulmonary cases ${ }^{25}$ which are included in the present series (patients 1 and 2).

In all our cases Gram stain at first was diagnostic of nocardial organisms confirming to be the most sensitive method to visualize Nocardiae in clinical specimens ${ }^{28}$, leading to definitively establish the diagnosis by a positive culture. As we have performed most of our diagnostic work up between 1977 and 1998, we have only one isolate of $N$. asteroides sensu stricto while the other seven isolates are classified only as $N$. asteroides complex.

Nocardia species most commonly infects humans through the respiratory tract by inhalation, being the lung the main organ affected. Clinical manifestations of lung and systemic nocardiosis are not specific and include anorexia, weight loss, productive cough, and oft pleural pain and often dyspnea $a^{3,16,22-24,26,34}$ as in our series, reason why its diagnosis is difficult. Lung nocardiosis was diagnosed in most of our patients $(72.3 \%)$ in our series, being in 16 patients localized while in one case it was systemic (patient 8 ). We had four more cases of systemic nocardiosis $(22.7 \%)$ which comprised cutaneous nocardiosis with arthritis (case 14), CNS nocardiosis (case 17), nocardiosis of small bowel (case 18) and a case of infective endocarditis of prosthetic aortic valve (case 20). And finally we had one case of mycetoma which is a localized skin infection that seldom disseminates, as in our patient.

We found as most common radiographic patterns of lung nocardiosis as others ${ }^{13}$ consolidations (11 cases, $64.7 \%$ ); in nine out of 11 cases the consolidations were already excavated with abscess formation; pulmonary nodules (five cases, 29.4\%) and pleural effusion (five cases, 29.4\%). Nocardiosis is commonly mistaken with bacterial pneumonia, tuberculosis, histoplasmosis, actinomycoses, lung cancer or bacterial abscess ${ }^{13}$.

Nocardia spp. may also cause primary disease in the skin by its traumatic introduction from soil. This primary skin infection is rare, often with a subacute course, presenting as cellulitis, lymphocutaneous disease or mycetoma in the immunocompetent patient; nocardial mycetomas may be caused by most of nocardial species but more frequently by $N$. brasiliensis, as occurred with patient 6 of our series. Mycetoma usually remains a localized lesion, as in our patient, rarely disseminating to the lungs and normal $\operatorname{skin}^{18}$.

In immunosuppressed patients nocardiosis is an opportunistic infection which more often disseminates to the CNS or to the skin, causing abscesses, nodules or cellulitis ${ }^{3,34}$ similarly to patient 14 of our series, who was admitted with multiple cutaneous abscesses and arthritis. He was classified as systemic nocardiosis: his multiple skin lesions and concomitant arthritis suggests haematological dissemination, but we could not identify the initial foci of nocardiosis. Cutaneous nocardiosis resulting from dissemination may be indistinguishable of cutaneous primary nocardiosis, so it is recommended to always search for a pulmonary primary foci ${ }^{34}$. Both our patients with nocardial skin infections were cured, despite of being a systemic disease in patient 14 .

Central nervous system nocardiosis occurs in approximately $22 \%$ of nocardiosis series ${ }^{3}$ and in $25 \%$ of all cases of lung nocardiosis, presumably being secondary to blood dissemination from an asymptomatic or healed lung infection ${ }^{15}$. CNS was the second most common organ involved in two large series of patients with nocardiosis, reaching an incidence of $43.5 \%{ }^{26}$ and $23 \%{ }^{24}$. The main symptoms and signs of cerebral nocardiosis include headache, nausea, vomiting and depressed consciousness and are not different from the symptoms of other bacterial abscesses ${ }^{15}$ or metastatic cancer ${ }^{30}$. In our series we had only one proved case of brain nocardiosis (patient 17) in whom a primary site of infection was never identified. Patients 10 and 16 had both lung nocardiosis and brain nodules at $\mathrm{CT}$ but their lesions were not either biopsed or resected, thus they can not be classified as CNS nocardiosis ${ }^{23}$. It is recommended brain CT be performed in every patient with nocardial infection, since it was noticed in a review of 120 cases of nocardial brain abscesses that $66 \%$ of the patients had a primary foci, being a subcutaneous/cutaneous foci in $20 \%$ and a pulmonary one in $38 \%$ of the cases. It was also reported high mortality to nocardial brain abscesses in immunosuppressed patients (55\%), contrasting with a mortality of $20 \%$ in non-immunocompromised patients ${ }^{21}$.

Intestinal nocardiosis has been reported very rarely ${ }^{7}$. Acute fulminant clinical course with peritonitis may be related to immunosuppression as occurred with one of our patients. Although high index of suspicion could reveal colonic or duodenal nocardiosis by endoscopic examination with biopsy, correct diagnosis may not be obtained before laparotomy.

Six reports of nocardial infective endocarditis of prosthetic valves were reported ${ }^{1,8,10-12,33}$. In four out of them ${ }^{1,8,10,11}$ blood cultures were positive, but only three patients survived after treatment: two patients underwent aortic valve replacement ${ }^{10,11}$, while the third one ${ }^{8}$ was cured only on antibiotic treatment, like our patient. In our patient it was not identified any other foci of nocardiosis and the infection occurred eight years after the surgery; he had two positive blood cultures to Nocardia spp. and transthoracic echocardiogram showed vegetations in the aortic valve prosthesis; it was fulfilled two major and two minor Duke's criteria ${ }^{9}$ being then a definitive clinical diagnosis of nocardial infective endocarditis, confirming the finding that it does not always require aortic prosthesis replacement ${ }^{8}$; and also suggesting that the use of IV sulfadiazine (six weeks) 
followed by PO TMP-SMX (six months) for the treatment of infective nocardial endocarditis may be successful in some cases.

We had four (18.2\%) organ recipients (two kidney and two liver recipients) with nocardiosis. The disease occurs mainly during the first year after transplant secondary to the highest dosis of corticosteroids ${ }^{20}$, as occurred in three transplanted patients of our series.

Our kidney transplant recipients both had lung nocardiosis. Patient 4 underwent living donor kidney transplantation and five years later was admitted due to bronchopneumonia and pleural effusion. $\mathrm{He}$ presented subhepatic and subphrenic abscesses where it was isolated $N$. asteroides complex as well as in the pleural effusion, further confirmed by CDC. Patient 5 had received a cadaveric kidney transplant being at this time hospitalized in the same ward. This latter patient was finally discharged after one month without any pulmonary lesion at Chest X-Ray. One month later she reported respiratory symptoms and was admitted with pulmonary consolidation and leukopenia. She had hemoptysis and a cavity appeared in the IRL along with pleural effusion in which was isolated $N$. asteroides complex. Both patients received TMP-SMX, getting cured. We think there may have been nosocomial transmission of nocardiosis in our hospital- even though we can not prove it by characterization of both nocardial strains $s^{2,5}$.

To our knowledge, this is the first case of pulmonary and systemic nocardiosis by $N$. asteroides complex in HIV-positive patient reported in our country so far. Despite the fact that the incidence of nocardiosis in AIDS patients is more than 140 times greater in average than that in general population ${ }^{14}$, it is not a common diagnosis in our country where most HIV-positive patients use prophylaxis with TMP- SMX. Our patient had $\mathrm{CD} 4<150$ cells per $\mu \mathrm{L}$ as reported ${ }^{32}$, not being on TMP/SMX prophylaxis for Pneumocystis jirovecii pneumonia. Due to the advanced immunodeficiency and many concomitant infections, in this very patient nocardiosis was not considered the main cause of death as in other reports ${ }^{32}$.

The predisposition to nocardiosis in patients with malignant diseases may be either related to the primary disease or to the use of cytostatic drugs ${ }^{4}$. Six out of the 22 cases here presented (27.3\%) had malignant diseases, being two out of them hematological cancer.

Immunodepression is a known risk factor for dying of pulmonary or systemic nocardiosis ${ }^{26}$; it was reported that in a group of 1000 patients with nocardiosis $64.3 \%$ were immunodepressed (with a mortality of $42.4 \%$ ); while in the group of non-immunodepressed patients with nocardiosis, mortality was $19.8 \%{ }^{3}$. In our series $68.2 \%$ of the patients are immunosuppressed with a mortality of $50 \%$.

Despite the fact that immunosuppressed patients usually have higher mortality, this finding was not confirmed in our series, since among the group of six non-immunosuppressed patients mortality was also high (50\%): one patient died with systemic disease (patient 8 ); other with lung bilateral nocardiosis with multiple cavitations and symptoms for less than three weeks (patient 21), both known risk factors for dying of nocardiosis ${ }^{26}$; and finally, patient 16 had lung nocardiosis and brain tumors of unknown aetiology; thus all three had a bad prognosis despite being non- immunosuppressed, reason why in this small group of six patients with systemic nocardiosis the mortality was similar between both groups.
Our patient with multiple nocardial brain abscesses died despite adequate surgical treatment, according to the high mortality (66\%) reported in such cases $^{21}$.

Disseminated nocardiosis is often a late-presenting and life threatening infection, most frequently secondary to hematogenous spread from a pulmonary infection ${ }^{23}$. Three out of our five cases of disseminated nocardiosis died $(60 \%)$, confirming the high mortality reported by the literature: patients with systemic nocardiosis have a mortality rate of $44 \% \%^{3,23}$; if their infection is bacteremic their mortality may be $50 \%{ }^{19}$ and if severely immunocompromised it can reach $85 \%$.

The weakness of our work is that we could not identify the species of Nocardia in all our 22 cases (diagnosed between 1977-1998), similarly to other reports ${ }^{9,16,22,30}$ which did not either identify the species of Nocardia in a range of $9 \%$ to $25 \%$ even though some had used molecular diagnostic methods; and also despite their diagnostic work up had been done either after $1988^{22,30}$ or after $1995^{16,28}$.

The delay in diagnosis and consequently the delay in treatment of our patients with systemic nocardiosis might have contributed to their death, although it had no reached a level of statistical significance in our series. It was previously suggested that the survival might be higher if the diagnosis was made earlier in the course of the disease ${ }^{26}$. We propose that this variable should be examined in a large series of nocardial infection, adjusting for other variables as immunosuppression and species of Nocardia, especially in the group of systemic nocardiosis. We think it is reasonable that advanced disease should have a worse prognosis; and high mortality might be due either to the predominance of infections caused by invasive nocardial species resistant to multiple antimicrobial agents as Nocardia farcinica ${ }^{6,29,31}$ which was not properly investigated in our series at the time.

\section{RESUMO}

\section{Infecções por Nocardia species: relato de 22 casos}

São apresentados 22 casos de infecção por Nocardia species entre 1977 e 1998, apresentando-se seu quadro clínico e evolução. Todos os pacientes cujos espécimes clínicos mostraram microorganismos sugestivos de Nocardia spp. à coloração de Gram, confirmados posteriormente por cultura, foram incluídos no estudo. Os dados dos pacientes que obtiveram cura foram comparados com aqueles dos pacientes que foram a óbito pelo programa EPIINFO versão 6.04; nível de significância menor que $5 \%$ foi considerado estatisticamente significativo. Foram obtidos 22 casos de infecção por Nocardia spp.: seis isolamentos identificados como Nocardia asteroides complex, um como Nocardia asteroides sensu stricto e outro como Nocardia brasiliensis, enquanto os restantes foram identificados como Nocardia spp. Tivemos 17 casos de nocardiose pulmonar (um com disseminação). Tivemos outros quatro casos de nocardiose sistêmica: múltiplos abscessos cerebrais (um); endocardite infecciosa de prótese valvular aórtica (um); nocardiose de intestino delgado (um); abscessos cutâneos múltiplos por Nocardia spp (um). Um paciente apresentou micetoma por Nocardia brasiliensis. Imunossupressão esteve presente em 15 pacientes $(68,2 \%)$, predominantemente por corticoterapia $(93,3 \%)$. Nossa mortalidade foi $41 \%$; a mortalidade dos pacientes com nocardiose sistêmica foi de $60 \%$. A nocardiose tem pior prognóstico 
em pacientes imunossuprimidos e em pacientes com nocardiose sistêmica.

\section{REFERENCES}

1. ALLEVATO, P.A.; EISSES, J.F.; MEZGER, E. et al. - Nocardia aortitis with perforation of the aorta. Hum. Path., 16: 743-746, 1985

2. BADDOUR, L.M.; BASELSKI, V.S.; HERR, M.J.; CHRISTENSEN, G.D. \& BISNNO, A.L. - Nocardiosis in recipients of renal transplants: evidence for nosocomial acquisition. Amer. J. Infect. Control, 14: 214-219, 1986.

3. BEAMAN, B.L. \& BEAMAN, L. - Nocardia species: host-parasite relationships. Clin. Microbiol. Rev., 7: 213-264, 1994.

4. BERKEY, P. \& BODEY, G.P. - Nocardial infection in patients with neoplastic disease. Rev. infect. Dis., 11: 407-412, 1989.

5. BLUMEL, J.; BLUMEL, E.; YASSIN, A.F.; SCHMIDT-ROTTE, H. \& SCHAAL, K.P. Typing of Nocardia farcinica by pulsed-field gel electrophoresis reveals an endemic strain as source of hospital infections. J. clin. Microbiol., 36: 118-122, 1998.

6. BOIRON, P.; PROVOST, F.; CHEVRIER, G. \& DUPONT, B. - Review of nocardial infections in France 1987 to 1990. Europ. J. clin. Microbiol. infect. Dis., 11: 709714, 1992.

7. BONACINI, M. \& WALDEN, J.M. - Nocardia brasiliensis peritonitis in a patient with AIDS. Amer. J. Gastroent., 85: 1432-1433, 1990.

8. DAIKOS, G.L.; SYRIOPOULOU, V.; HORIANOPOULOU, M. et al. - Successful antimicrobial chemotherapy for Nocardia asteroides prosthetic valve endocarditis. Amer. J. Med., 115: 330-332, 2003.

9. DURACK, D.T.; LUKES, A.S. \& BRIGHT, D.K. - New criteria for diagnosis of infective endocarditis: utilization of specific echocardiographic findings. Duke Endocarditis Service. Amer. J. Med., 96: 200-209, 1994.

10. EIGEL, P.; ELERT, O.; HOPP, H. et al. - Nocardial endocarditis after aortic valve replacement. Reports of two cases. Scand. J. thorac. cardiovasc. Surg., 22: 289290, 1988.

11. ERTL, G.; SCHAAL, K.P. \& KOCHSIEK, K. - Nocardial endocarditis of an aortic valve prosthesis. Brit. Heart J., 57: 384-386, 1987.

12. FALK, R.H.; DIMOCK, F.R. \& SHARKEY, J. - Prosthetic valve endocarditis resulting from Nocardia spp. Brit. Heart J., 41: 125-127, 1979.

13. FEIGIN, D.S. - Nocardiosis of the lung: chest radiographic findings in 21 cases. Radiology, 159: 9-14, 1986.

14. FILICE, G.A. - Nocardiosis in persons with human immunodeficiency virus infection, transplant recipients, and large, geographically defined populations. J. Lab. clin. Med., 145: 156-162, 2005.

15. FILICE, G.A. - Nocardiosis. In: NIEDERMAN, M.S., SAROSI, G.A. \& GLASSROTH, J., ed. Respiratory infections. 2. ed. Philadelphia, Lippincott Williams, 2001. v. 20, p. 457-466.

16. HUI, C.H.; AU, W.K.; ROWLAND, K.; SLAVOTINE, J.P. \& GORDON, D.L. - Pulmonary nocardiosis re-visited: experience of 35 patients at diagnosis. Resp. Med., 97: 709717,2003

17. KAGEYAMA, A.; YAZAWA, K.; ISHIKAWA, J. et al. - Nocardial infections in Japan from 1992 to 2001, including the first report of infection by Nocardia transvalensis. Europ. J. Epidem., 19: 383-389, 2004.
18. KAHN, F.W.; GORNICK, C.C. \& TOFTE, R.W. - Primary cutaneous Nocardia spp. infection with dissemination. Amer. J. Med., 70: 859-863, 1981.

19. KONTOYIANNIS, D.P.; RUOFF, K. \& HOOPER, D.C. - Nocardia bacteremia. Report of 4 cases and review of the literature. Medicine (Baltimore), 77: 255-267, 1998.

20. LERNER, P.A. - Nocardia species. In: MANDELL, G.L.; BENNETT, J.E. \& DOLIN, R., ed. Principles and practice of infectious diseases. 5. ed. New York, Churchill Livingstone, 1995. p. 2273-2280.

21. MAMELAK, A.N.; OBANA, W.G.; FLAHERTY, J.F. \& ROSENBLUM, M.L. - Nocardial brain abscess: treatment strategies and factors influencing outcome. Neurosurgery, 35: $622-631,1994$

22. MATULIONYTE, R.; ROHNER, P.; UÇKAY, I.; LEW, D. \& GARBINO, J. - Secular trends of Nocardia infection over 15 years in a tertiary care hospital. J. clin. Path., 57: 807-812, 2004.

23. McNEIL, M.M. \& BROWN, J.M. - The medically important aerobic actinomycetes: epidemiology and microbiology. Clin. Microbiol. Rev., 7: 357-417, 1994.

24. PALMER, D.L.; HARVEY, R.L. \& WHEELER, J.K. - Diagnostic and therapeutic considerations in Nocardia asteroides infection. Medicine (Baltimore), 53: 391-401, 1974.

25. PETRILLO, V.F.; SEVERO, L.C.; LONDERO, A.T. \& PORTO, N.S. - Pulmonary nocardiosis report of the first two Brazilian cases. Mycopathologia (Den Haag), 66: $17-20,1978$.

26. PRESANT, C.A.; WIERNIK, P.H. \& SERPICK, A.A. - Factors affecting survival in nocardiosis. Amer. Rev. respir. Dis., 108: 1444-1448, 1973.

27. SANTAMARIA SABER, L.T.; FIGUEIREDO, J.F.; SANTOS, S.B. et al. - Nocardia infection in renal transplant recipient: diagnostic and therapeutic considerations. Rev. Inst. Med. trop. S. Paulo, 35: 417-421, 1993.

28. SAUBOLLE, M.A. \& SUSSLAND, D. - Nocardiosis: review of clinical and laboratory experience. J. clin. Microbiol., 41: 4497-4501, 2003.

29. SCHAAL, K.P. \& LEE, H.J. - Actinomycete infections in humans: a review. Gene, 115 201-211, 1992

30. TORRES, H.A.; REDDY, B.T.; RAAD, I.I. et al. - Nocardiosis in cancer patients. Medicine (Baltimore), 81: 388-397, 2002.

31. TORRES, O.H.; DOMINGO, P.; PERICAS, R. et al. - Infection caused by Nocardia farcinica: case report and review. Europ. J. clin. Microbiol. infect. Dis., 19: 205212, 2000.

32. UTTAMCHANDANI, R.B.; DAIKOS, G.L.; REYES, R.R. et al. - Nocardiosis in 30 patients with advanced human immunodeficiency virus infection: clinical features and outcome. Clin. infect. Dis., 18: 348-353, 1994.

33. VLACHAKIS, N.D.; GAZES, P.C. \& HAIRSTON, P. - Nocardial endocarditis following mitral valve replacement. Chest, 63: 276-278, 1973.

34. WILSON, J.P.; TURNER, H.R.; KIRCHNER, K.A. \& CHAPMAN, S.W. - Nocardial infections in renal transplant recipients. Medicine (Baltimore), 68: 38-57, 1989.

35. YU, V.L.; CHIOU, C.C.; FELDMAN, C. et al. - An international prospective study of pneumococcal bacteremia: correlation with in vitro resistance, antibiotics administered and clinical outcome. Clin. infect. Dis., 37: 230-237, 2003.

Received: 3 May 2006

Accepted: 28 November 2006 